\title{
Experimental and Finite Element Analysis on Chip Formation Mechanism in Machining of Elastomers
}

\author{
Rajesh Nayak, Raviraj Shetty and Sawan Shetty
}

\begin{abstract}
Computer simulation of metal cutting processes using the Finite Element Analysis (FEA) method are routinely practiced in today's industry. It is known from the theory of metal cutting that an examination of machined chips provides the cheapest and the most effective way of understanding the machining characteristics of a material.

This paper discusses experimental work and finite element analysis to investigate the mechanism of chip formation during machining of Elastomer. Focus of this study is on understanding the influence of different cutting parameters on chip formation mechanism. From the experimental tests, it has been concluded that the morphology of rubber chips can be categorized into continuous ribbon-like chips with a smooth machined surface, segmented chips with a rough machined surface, and discontinuous chips with an even worse surface finish. Continuous ribbon-like chips are associated with a smooth surface finish, which occurs with large rake angle tools. Further from Finite Element Analysis it was observed that at lower rake angle, discontinuous chips are formed and Continuous ribbon-like chip occurs with large rake angle.
\end{abstract}

Keywords--- Chip Formation Mechanism, Elastomers, Finite Element Analysis, Orthogonal Machining

\section{INTRODUCTION}

$\mathrm{E}$ LASTOMERS have been used as an engineering material for nearly 180 years in various military equipment's and industries in applications such as liner layers of armored vehicles, tires, springs, shock isolators, noise and Vibration absorbers, seals, and electrical and thermal insulators. An elastomer can be defined as, "a macromolecular material, which, at room temperature, is capable of recovering substantially in shape and size after removal of a deforming force [1]. Most elastomer parts are manufactured using a molding rather than machining process, to manufacture elastomer parts with complicated shapes, such as tire and footwear tread patterns, a set of molds must first be produced. However, there are many disadvantages associated with molding elastomers including high cost, labor-intensive and time consuming process of mold fabrication and the inflexibility of a mold to design changes. For these reasons, machining offers an attractive alternative for manufacturing elastomer components.

Rajesh Nayak, Assistant Professor, Mechanical, MIT/Manipal, Manipal, India, E-mail: rajesnayak@gmail.com

Raviraj Shetty, Associate Professor, Aeronautical and Automobile Engineering, MIT/ Mnipal, Manipal, India, E-mail: rrshetty2@rediffmail.com Sawan Shetty, Assistant Professor, Mechanical, MIT/Manipal, Manipal, India, E-mail: sawanshetty@yahoo.co.in

\section{LETERATURE SURVEY}

Very little research on elastomer machining has been conducted because of the complex material response of elastomers and the complexity of the machining process itself. Jin and Murakawa, [2] have carried out experiments with variety of carbide end mills of various sizes and helix angles to mill grooves in three types of elastomers; H-NBR, Norbornone rubber, and silicone rubber at various cutting speeds . They have reported that at high helix angle cutters and high speeds yields smoother machined surfaces and lower forces. Shih et al [3] investigated the machining of elastomers with sharp woodworking tools and under cryogenic conditions and reported that proper selection of end mill geometries, process parameters, and fixture stiffness, clean grooves can be machined in elastomers. It was also shown that cryogenic cooling of an elastomer workpiece is beneficial in achieving a smooth machined surface. Strenkowski et al [4] carried out orthogonal rubber cutting experiments and examined the effects of various machining parameters on chip morphology, machined surface roughness. Feed rate and rake angle were found to have a significant effect on the types of chips generated during orthogonal cutting. Long and continuous ribbon-like chips and corresponding smooth machined surfaces were produced for high feed speed conditions and large rake angle tools. Strenkowski et al [5] have developed wedge indentation models to investigate chip formation during incipient cutting prior to material separation. Shih et al [6-7] have done analysis on rubber workpiece to study its stiffness using ANSYS. In this work, the design of the workpiece fixture was found to be a critical factor in achieving good surface finish in end milling of elastomers because of the low elastic modulus. Dhokia et al [8] have discovered the novel concept of cryogenic CNC machining of elastomers and the development of a process control system for cryogenic CNC machining. Raviraj Shetty et al [9] involved experimental work and finite element analysis to investigate the mechanism of chip formation during machining of DRACs using ANSYS/LS-DYNA.

This paper discusses experimental work and finite element analysis to investigate the mechanism of chip formation during machining of Elastomer.

\section{EXPERIMENTAL}

The experiments were carried out in PSG A141 lathe (2.2 KW) using High Speed Steel (HSS) under ambient and cryogenic conditions. In cryogenic condition, the rubber stiffness was increased by cooling the workpiece in liquid nitrogen before conducting the cutting tests; Figure-1 shows HSS tools with varying rake angles. Elastomer workpiece 
specimens having outside diameter of $60 \mathrm{~mm}$ and a wall thickness of $15 \mathrm{~mm}$ was used in this research. Figure-2 shows the SEM image of Elastomer. Turning method as machining process was selected. Specification and mechanical properties of test sample is shown in Table-1.

The selected cutting tool was High Speed Steel (HSS) with different rake angle, for machining of elastomer. The details of cutting tool are shown in Table- 2 respectively. Table- 3 shows the cutting parameters and working condition parameters.

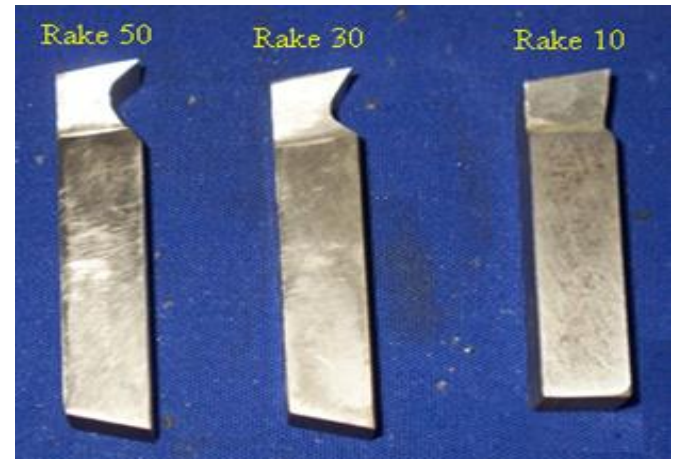

Figure 1: HSS Tools with Varying Rake Angles

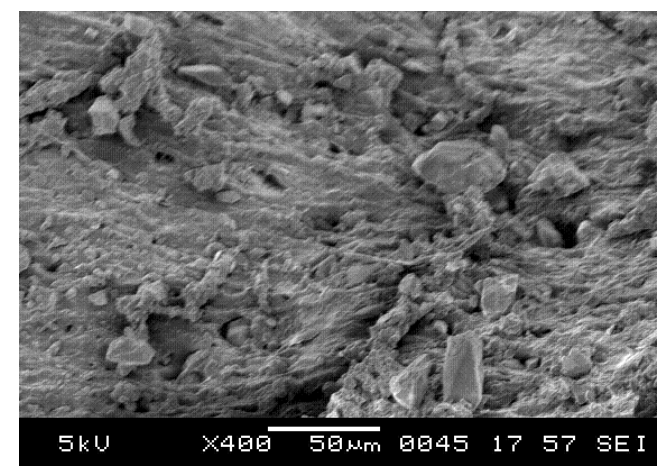

Figure 2: SEM Image of Elastomer

Table 1: Specification and Mechanical Properties of Test Sample

\begin{tabular}{|c|c|c|c|c|}
\hline Material & $\begin{array}{c}\text { Hardness } \\
\text { Shore A }\end{array}$ & $\begin{array}{c}\text { Tensile } \\
\text { strength } \\
\left(\mathrm{N} / \mathrm{mm}^{2}\right. \\
)\end{array}$ & $\begin{array}{c}\text { Elongatio } \\
\mathrm{n} \text { at break } \\
(\%)\end{array}$ & $\begin{array}{c}\text { Working } \\
\text { temperat } \\
\text { ure }\left({ }^{0} \mathrm{C}\right)\end{array}$ \\
\hline Elastomer & 80 & 15.0 & 200 & 95 \\
\hline
\end{tabular}

Table 2: Details of Cutting Tool Used For Experimentation

\begin{tabular}{|c|c|}
\hline $\begin{array}{c}\text { Tool geometry } \\
\text { Specification }\end{array}$ & $\begin{array}{c}\text { Rake angle: } 10^{0}, 30^{\circ}, 50^{\circ} \\
\text { Clearance angle: } 5^{0}\end{array}$ \\
\hline Tool & High Speed Steel (HSS) \\
& \\
\hline
\end{tabular}

Table 3: The Cutting Parameters and Working Condition Parameters

\begin{tabular}{|c|c|c|c|c|c|c|c|}
\hline $\begin{array}{c}\text { Working } \\
\text { conditions }\end{array}$ & $\begin{array}{c}\text { Rake } \\
\text { angles(deg) }\end{array}$ & & $\begin{array}{l}\text { Feed } \\
\mathrm{mm} / \mathrm{re}\end{array}$ & & \multicolumn{3}{|c|}{$\begin{array}{l}\text { Cutting speed } \\
\text { (rpm) }\end{array}$} \\
\hline $\begin{array}{l}\text { Dry } \\
\text { cutting }\end{array}$ & $\begin{array}{lll}10 & 30 & 50\end{array}$ & 0.11 & 0.18 & 0.25 & 360 & 580 & 800 \\
\hline $\begin{array}{l}\text { Cryogenic } \\
\text { cutting }\end{array}$ & $\begin{array}{lll}10 & 30 & 50\end{array}$ & 0.11 & 0.18 & 0.25 & 360 & 580 & 800 \\
\hline
\end{tabular}

\section{FINITE ELEMENT ANALYSIS}

The numerical simulation and resulting computations were performed using a finite element analysis with ANSYS software program [10].

ANSYS is a finite element program with capabilities, ranging from a simple, linear, static analysis to a complex, nonlinear, transient dynamic analysis [11]. For large deformation dynamics, quasi-static problems with large deformations, multiple nonlinearities and complex contact/impact problems, ANSYS combines with LS-DYNA explicit dynamics finite element program with the powerful pre-and post-processing capabilities of the ANSYS program[10].

The explicit method of solution used by LS-DYNA provides fast solutions in a short time for the above situations. Using this integrated product, one can model the structure in ANSYS, obtain the explicit dynamic solution via LS-DYNA, and review results using the standard ANSYS post processing tools. The procedure for an explicit dynamic analysis is similar to any other analysis that is available in the ANSYS 11.0 program. A typical finite element analysis on ANSYS/LS-DYNA has three distinct steps: (a) building the Finite Element model, (b) applying loading and obtaining solution, and (c) reviewing the results [10].

\section{RESULTS AND DISCUSSIONS}

The form of chip produced is one of the major parameters influencing productivity in metal cutting industry. Generally, there are three types of chip forms during machining of elastomers, (1) Continuous ribbon-like chips, (2) segmented chips, (3) discontinuous chips.

\section{A. Chip Formation Mechanism (Experimental)}

Chip size, shape and types provide useful information for understanding the chip formation process of rubber machining. Chips were collected and analyzed after the cutting tests. Figure-3 and Figure-4 shows various SEM images of chip types that correspond to the relative machined surfaces under ambient and cryogenic cutting conditions. It can be seen that the chip types are closely related to the machined surface finishes.

From previous and current cutting tests, it has been shown that the morphology of rubber chips can be categorized into three basic types: (1) continuous ribbon-like chips with a smooth machined surface, (2) segmented chips with a rough 
machined surface, and (3) discontinuous chips with an even worse surface finish. Continuous ribbon-like chips are associated with a smooth surface finish, which occurs with large rake angle tools and under cryogenic cooled workpiece conditions. In contrast, discontinuous chips are associated with a rough machined surface that results from cutting with small rake angle tools at ambient temperatures.

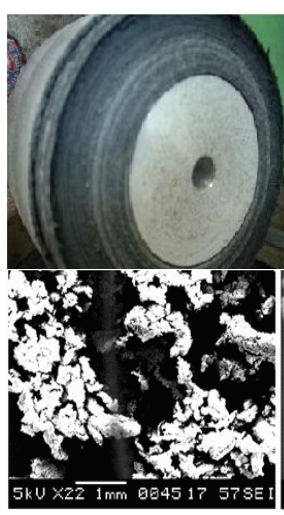

(a)

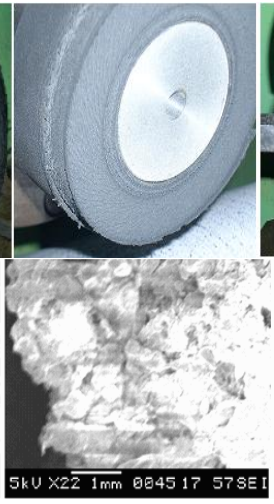

(b)

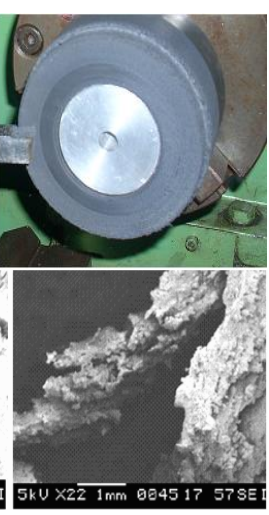

(c)
Figure 3: Surface Finish (Top) and SEM Images of Chips (Bottom) Formed From Experimental Runs under Ambient Cutting Condition (a) $10^{\circ}$ Rake (b) $30^{\circ}$ Rake (c) $50^{\circ}$ Rake

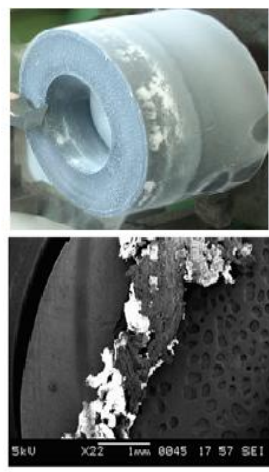

(a)

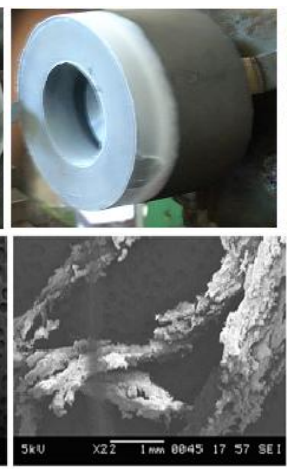

(b)

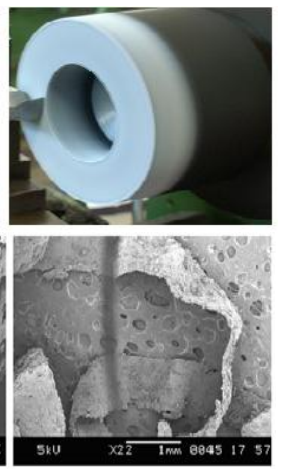

(c)
Figure 4: Surface Finish (Top) and SEM Images of Chips (Bottom) Formed From Experimental Runs under Cryogenic Cutting Condition (a) $10^{\circ}$ Rake (b) $30^{\circ}$ Rake (c) $50^{\circ}$ Rake

\section{B. Chip formation mechanism (Finite Element Modeling)}

ANSYS/LS-DYNA supplies several formulations for numerical modeling: Lagrangian, Eulerian and Arbitrary Lagrangian Eulerian (ALE). Among them, Lagrangian and ALE formulations supply approaches to chip separation in the chip formation process [11-17].

Lagrangian formulation tracks discrete material points. Chip separation is normally performed along predetermined lines of elements on the moving path of the tool edge, by deleting elements ahead the tool edge when element failure criterion, such as strain failure criterion, is reached. In addition, the number and size of deleted elements affect produced chip thickness, and fine elements improve simulated result whereas at the same time increase sharply the calculation time and cost. Therefore, sharp tool is most frequently used in chip formation modeling, because the separation line is obvious and by using very fine elements

along this line and defining strain failure only to these line elements [18].

In normal turning operation, cutting depth, feed rate and cutting speed are kept constant, and steady state will be reached within several seconds after the entrance of tool edge into work material. Knowledge about the shape and geometry of the formed chip is the prerequisite of steady-state modelling, which comes from experiment or simulation. This paper supplies a complete modelling method of initial chip formation. The work has a size of $6 \mathrm{~mm} \times 1 \mathrm{~mm}$, Moreover, in this analysis, the cutting tool is considered as rigid body, whereas workpiece has to be modelled as a deformable body in order to obtain the necessary chip formation mechanism. At the beginning, the tool is at the right side of the work, and as the tool advances, according to the surface crack mechanism a crack initiates on the free surface, extends to the cutting edge, and stops somewhere within the chip due to excessive compression. If a small crack occurs, it will trigger adiabatic shearing, but it is found that shear localization could also occur without a preexisting crack. Therefore, the determination of whether a crack exists will help clarify the chip formation mechanism.

Figure-5 shows the form of the chips during the machining of Elastomer at varying rake angles under constant cutting speeds and depth of cut. At lower rake angle, discontinuous chips are formed. Continuous ribbon-like chips occurs with large rake angle tools.
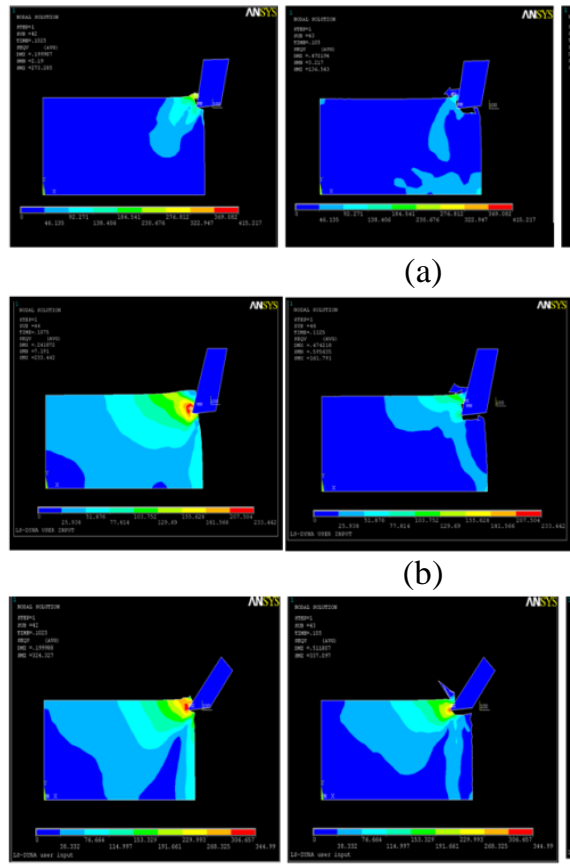

(c)

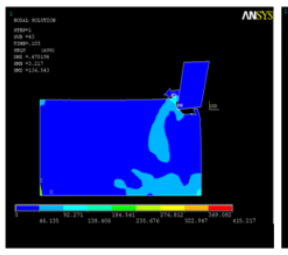

(a)

(b)

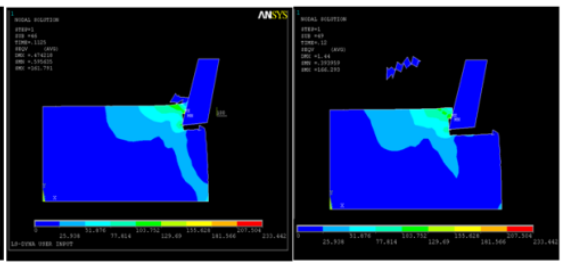

Figure 5: Comparison of Chip Formation under Different Cutting Condition (a) $10^{\circ}$ rake (b) $30^{\circ}$ rake (c) $50^{\circ}$ rake

\section{CONCLUSIONS}

The morphology of rubber chips can be categorized into three basic types: (1) continuous ribbon-like chips with a smooth machined surface, (2) segmented chips with a rough machined surface, and (3) discontinuous chips with an even 
worse surface finish, respectively. Continuous ribbon-like chips are associated with a smooth surface finish, which occurs with large rake angle tools. In contrast, discontinuous chips are associated with a rough machined surface that results from cutting with small rake angle tools. The simulations show good agreement with these experimental results.

\section{REFERENCES}

[1] ASTM D1566-00, Standard Terminology Relating to Rubber, American Society for Testing of Materials, 2000

[2] M.Jin and M. Murakawa, "High-Speed Milling of Rubber (1st Report), Fundamental Experiments and Considerations for Improvement of Work Accuracy," Journal of the Japan Society for Precision Engineering, Vol. 64, 6, Pp. 897-901, 1998.

[3] A.J.Shih, M. A. Lewis, J. Luo, and J. S. Strenkowski, "End Milling of Elastomers,Fixture Design and Tool Effectiveness for Material Removal," ASME Journal of Manufacturing Science and Engineering, Vol. 126, Pp. 115-123, 2004.

[4] J.S. Strenkowski, A.J.Shih, S.Rodkwan, and M.A. Lewis, Machining of Elastomers - Experimental and Numerical Investigation, 2003 NSF Design, Service and Manufacturing Grantees and Research Conference, Birmingham, Alabama,2003.

[5] J.S.Strenkowski, J.Yan, A.J.Shih and J. Luo, "Improving the Machinability of Elastomers with Induction Heated Tools and Finite Element Cutting Models," NSF Design, Service and Manufacturing Grantees and Research Conference Proceedings, Scottsdale, AZ, 2005.

[6] A.J.Shih, M.A.Lewis and J.S.Strenkowski, "End Milling of Elastomers,Fixture Design and Tool Effectiveness for Material Removal," ASME Journal of Manufacturing Science and Engineering, Vol. 126, Pp. 115-123, 2004.

[7] A.J.Shih, M. A. Lewis, J. Luo, and J. S. Strenkowski, "Chip Morphology and Forces in End Milling of Elastomers," ASME Journal of Manufacturing Science and Engineering, Vol. 126, Pp. 124-130, 2004.

[8] V.G. Dhokia, S.T.Newman,P. Crabtree,M. P.Ansell, "A process control system for cryogenic CNC elastomer machining," Journal of Robotics and Computer-Integrated Manufacturing, Vol.27, Pp.779-784, 2011.

[9] Raviraj Shetty, Laxmikanth Keni, R. Pai and V. Kamath, "Experimental and Analytical study on chip formation mechanism in machining of DRACs," ARPN Journal of Engineering and Applied Sciences, Vol. 3, No. 5, Pp. 27-32, 2008.

[10] ANSYS/LS-DYNA Reference Manual, Release 10, Livermore Software Technology Corporation, Livermore, CA.

[11] J.S.Strenkowski and J.T. Carroll, "A Finite Element Model of Orthogonal Metal Cutting,”ASME J. Engg. Ind., Vol. 107, Pp.349-354, 1985.

[12] J.S. Strenkowski, K.J. Moon, Finite element prediction of chip geometry, ASME J. Eng. Indust. 112, Pp 313-318, 1990.

[13] L. Zhang, "On the Separation Criteria in the Simulation of Orthogonal Metal Cutting Using the Finite Element Method," J. Mat. Proc. Technol., Vol. 89: Pp.273-278, 1999.

[14] Dr. Maan Aabid Tawfiq, Suha Kareem Shahab, “ A finite element analysis of orthogonal machining using different tool head geometries", Journal of Engineering \& Technology, Vol. 25, Pp. 569-583,2007.

[15] M. Baeker, "An Investigation of the Chip Segmentation Process Using Finite Elements" Technische Mechanic, Band 23, Pp. 1-9, 2003.

[16] Y.B. Guo, David W. Yen, "A FEM study on mechanisms of discontinuous chip formation in hard machining" Journal of Materials Processing Technology, vol.155-156, pp.1350-1356, 2004.

[17] M. Mahnama, M.R. Movahhedy, "Application of FEM simulation of chip formation to stability analysis in orthogonal cutting process" Journal of Manufacturing Processes, doi:10.1016/j.jmapro.2011.12.007, 2012.

[18] Zhang, B., Bagchi, A "Finite Element Simulation of Chip Formation and commparison with Machining Experiment" Journal of Engineering for Industry, Transactions of the ASME, Vol.116, Pp. 289-297, 1994. 